\title{
TU/e emonownen

\section{Scalable Optical Packet Switches for Multiple Data Formats and Data Rates Packets}

\section{Citation for published version (APA):}

Calabretta, N., Wang, W., Ditewig, A. M. H., Raz, O., Gomez Agis, F., Zhang, S., Waardt, de, H., \& Dorren, H. J. S. (2010). Scalable Optical Packet Switches for Multiple Data Formats and Data Rates Packets. IEEE Photonics Technology Letters, 22(7), 483-485. https://doi.org/10.1109/LPT.2010.2040993

DOI:

10.1109/LPT.2010.2040993

Document status and date:

Published: 01/01/2010

\section{Document Version:}

Publisher's PDF, also known as Version of Record (includes final page, issue and volume numbers)

\section{Please check the document version of this publication:}

- A submitted manuscript is the version of the article upon submission and before peer-review. There can be important differences between the submitted version and the official published version of record. People interested in the research are advised to contact the author for the final version of the publication, or visit the $\mathrm{DOI}$ to the publisher's website.

- The final author version and the galley proof are versions of the publication after peer review.

- The final published version features the final layout of the paper including the volume, issue and page numbers.

Link to publication

\section{General rights}

Copyright and moral rights for the publications made accessible in the public portal are retained by the authors and/or other copyright owners and it is a condition of accessing publications that users recognise and abide by the legal requirements associated with these rights.

- Users may download and print one copy of any publication from the public portal for the purpose of private study or research.

- You may not further distribute the material or use it for any profit-making activity or commercial gain

- You may freely distribute the URL identifying the publication in the public portal.

If the publication is distributed under the terms of Article 25fa of the Dutch Copyright Act, indicated by the "Taverne" license above, please follow below link for the End User Agreement:

www.tue.nl/taverne

Take down policy

If you believe that this document breaches copyright please contact us at:

openaccess@tue.nl

providing details and we will investigate your claim. 


\title{
Scalable Optical Packet Switches for Multiple Data Formats and Data Rates Packets
}

\author{
N. Calabretta, Member, IEEE, W. Wang, T. Ditewig, O. Raz, F. Gomez Agis, S. Zhang, H. de Waardt, and \\ H. J. S. Dorren, Member, IEEE
}

\begin{abstract}
We demonstrate an optical packet switch (OPS) subsystem employing in-band labeling to allow for transparent routing of packets with multiple data formats and data bit rates. Packets employing in-band labels can be processed without the need to reconfigure the label processor and the switch when changing data format and bit-rate. The label processor is based on asynchronous optical signal processing in combination with a simple electronic combinatory network. This makes the label processor capable to process a large number of labels with low latency time $(<3 \mathrm{~ns})$ without complicated and power-hungry high-speed packet clock recovery and serializer/deserializer circuits. Experimental results show error-free operation of $1 \times 64$ OPS subsystem for $160-G b / s$ return-to-zero $\mathrm{ON}-\mathrm{OFF}$ keying and $120-\mathrm{Gb} / \mathrm{s}$ nonreturn-to-zero differential phase-shift keying multiwavelength packets.
\end{abstract}

Index Terms-Fiber Bragg grating (FBG), label processor, optical packet switching, optical signal processing, optical switch.

\section{INTRODUCTION}

$\mathbf{T}$ HE exponential growth of the Internet data traffic will demand high capacity optical networks. It might occur that high-capacity optical links will carry optical packets at data rates above $100 \mathrm{~Gb} / \mathrm{s}$ using a variety of data formats such as return-to-zero (RZ) data packets [1], multiwavelength optical packets that might have highly spectral efficient modulation formats, such as differential (quadrature) phase-shift keying (D(Q)PSK) [2], orthogonal frequency-division multiplexing (OFDM) [3], $M$-quadrature amplitude modulation (QAM) [4]. On the other hand, routing of packets by today's electronic circuit switching may have fundamental limits due to the speed and the scalability of multirack electronic switching fabrics, and the associated power consumption by optoelectronic conversions [5].

Switching of the optical packets transparently in the optical domain eliminates power-hungry optoelectronic conversions [6]-[10]. However, there are several issues to be addressed for realizing such an optical packet switch (OPS) subsystem. The OPS subsystem should be able to handle optical packets with multiple data formats. This implies that both the label processor, which determines the packet destination and controls the switching fabric, as well as the optical switching fabric,

Manuscript received November 10, 2009; revised December 21, 2009; accepted January 07, 2010. First published February 02, 2010; current version published March 10, 2010. This work was supported by the Netherlands Science Foundation (NWO) and by the Technology Foundation (STW) through the NRC Photonics and Vi programs.

The authors are with COBRA Research Institute, Eindhoven University of Technology, Eindhoven, Den Dolech 2, 5600 MB, The Netherlands (e-mail: n.calabretta@tue.nl).

Color versions of one or more of the figures in this letter are available online at http://ieeexplore.ieee.org.

Digital Object Identifier 10.1109/LPT.2010.2040993 should operate independently of the data format and data rate of the packets. The OPS subsystem should be scalable, which means that the number of input-output ports is not limited by switch architecture. For instance, a large $N \times N$ switching matrix based on Clos architecture [11] can be realized starting from a $1 \times N$ switch. Essential in realizing a $1 \times N$ optical switch is the implementation of a scalable label processor. Moreover, the OPS subsystem should introduce little latency for increasing the node throughput.

In this work, we demonstrate an OPS subsystem employing in-band labeling to allow for transparent routing of multiwavelength packets with multiple data formats and at different data bit rates. The OPS subsystem employs a scalable, asynchronous, and low latency label processor. The label processor can operate for $160-\mathrm{Gb} / \mathrm{s}$ optical time-division multiplexing (OTDM) RZ ON-OFF keying (OOK) and 120-Gb/s $(12 \times 10 \mathrm{~Gb} / \mathrm{s})$ nonreturn-to-zero DPSK (NRZ-DPSK) multiwavelength packets, and therefore, the label processor and the switch do not need to be reconfigured when changing data format. We demonstrate for the first time a transparent $1 \times 64$ OPS for OOK and DPSK data packets with low penalty.

\section{In-BAND LABELING TECHNIQUE}

Generally, optical packets at high data rate $B$ can be generated in serial by using OTDM techniques, or in parallel by using $N$ colored channels; each channel has bit rate $B / N$. Both the OTDM packets and $N$ channels can be encoded by many modulation formats. We encode the address information of optical packets by in-band labels, i.e., the wavelengths of the labels are chosen within the bandwidth of the payload. We have already validated this technique for $160-\mathrm{Gb} / \mathrm{s}$ OTDM packets; the labels were inserted within the spectrum of the OTDM signal [see Fig. 1(a)]. For the DPSK multiwavelength packets, we use the same label wavelengths, but they are spectrally located in the notches of the spectra of the multiwavelength payload [see Fig. 1(b)] [9], [10]. Each label has a binary value and is OOK encoded with a pulse duration equal to the payload. Thus, $2^{N}$ addresses can be encoded by using $N$ wavelengths. This makes this technique scalable within the limited payload bandwidth. We demonstrate that by using the in-band labeling technique, the all-optical label extractor (AOLE) and the combinatory network do not need to be reconfigured to process any packets regardless of the data payload formats.

\section{EXPERIMENTAL SETUP}

The experimental setup to demonstrate the OPS operation of packets with multiple modulation format and in-band labels is shown in Fig. 1. At the transmitter side, we generated payloads with two types of modulation formats. First, $160-\mathrm{Gb} / \mathrm{s}$ OOK payload centered at $1546 \mathrm{~nm}$ is generated by time-multiplexing 

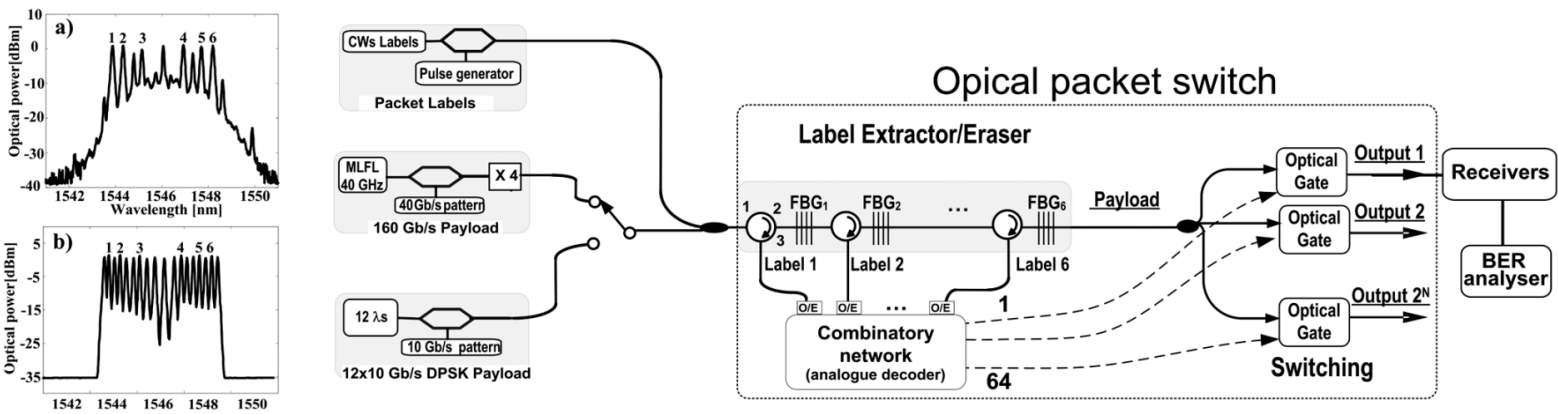

Fig. 1. Experimental setup. Packets with two types of modulation formats and six OOK labels are generated and processed by the packet switch. (a) 160-Gb/s RZ-OOK packets with the six labels; (b) 120-Gb/s NRZ-DPSK with the six labels.

40-Gb/s modulated optical pulses. The 1.4-ps optical pulses make the -20 -dB bandwidth of the payload to be $5 \mathrm{~nm}$. Second, $120-\mathrm{Gb} / \mathrm{s}$ NRZ-DPSK multiwavelength payload was emulated by using two time 6 channels with wavelengths from 1544.1 to $1548 \mathrm{~nm}$ on a $50-\mathrm{GHz}$ grid by using a $10-\mathrm{GHz}$ phase modulator. The data format transparent optical switches employed in the experiment makes channel decorrelation redundant.

The optical address coupled to the payloads was generated by encoding six labels with the same duration as the packet payload and with wavelengths $\lambda_{1}=1543.88 \mathrm{~nm}, \lambda_{2}=1544.36 \mathrm{~nm}$, $\lambda_{3}=1545.16 \mathrm{~nm}, \lambda_{4}=1546.92 \mathrm{~nm}, \lambda_{5}=1547.72 \mathrm{~nm}$, and $\lambda_{6}=1548.2 \mathrm{~nm}$. Note that the labels are located within the optical spectra of the two types of payload [see Fig. 1(a) and (b)].

The optical packets are fed into the OPS. The schematic of the $1 \times N$ OPS is shown in Fig. 1. It consists of an AOLE that separates the labels and payload. The separated payload is broadcasted into the optical gates, while the extracted labels are processed by the combinatory network, which provides the control signals for driving the optical gates. The AOLE separates the labels and payload by using a cascade of six narrow-bandwidth fiber Bragg gratings (FBGs) centered at the labels wavelengths and optical circulators. The FBGs have a Gaussian profile with $98 \%$ of reflectivity and $6 \mathrm{GHz}$ at -3 -dB bandwidth to avoid significant slicing of the spectrum of the payload that may lead to distortions. The labels output in parallel from the AOLE. This avoids complicated packet-based clock-recovery and electrical serial-to-parallel conversion. The labels are processed by the combinatory network, which is an asynchronous electronic analogue decoder. The output signals control the optical gates. The combinatory network can process a large number of labels without increasing the latency by using several chips in parallel. Note that since the labels have the same duration as the payload, the control signals generated by the combinatory network have a duration equal to the payload. This makes flip-flops redundant and allows for operation on packets with variable length. The optical gates are based on electrooptic $\mathrm{LiNbO}_{3}$ switches to guarantee transparent switching of the packets with multiple data formats. The switched optical packets are then received and analyzed by the BER tester.

\section{RESULTS}

First, we investigate the compatibility of in-band labels with payloads with multiple modulation formats. We fed into the OPS packets with six in-band labels and data payload with different formats. We evaluate the quality of the payloads after filtering the in-band labels. The optical spectra of the packets before and after the label extractor and the BER measurements
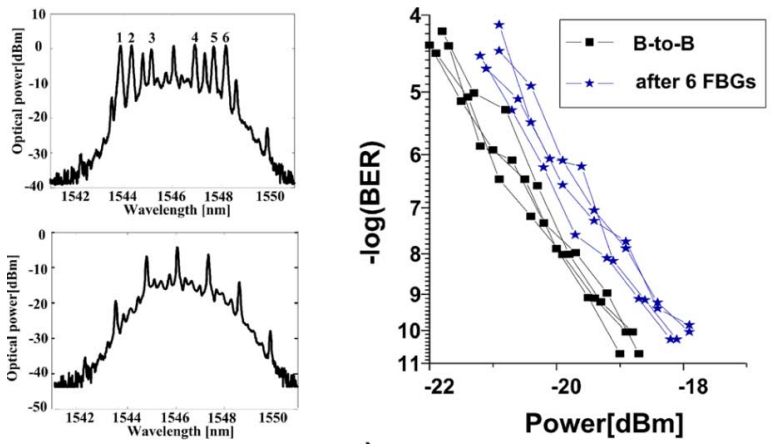

a)
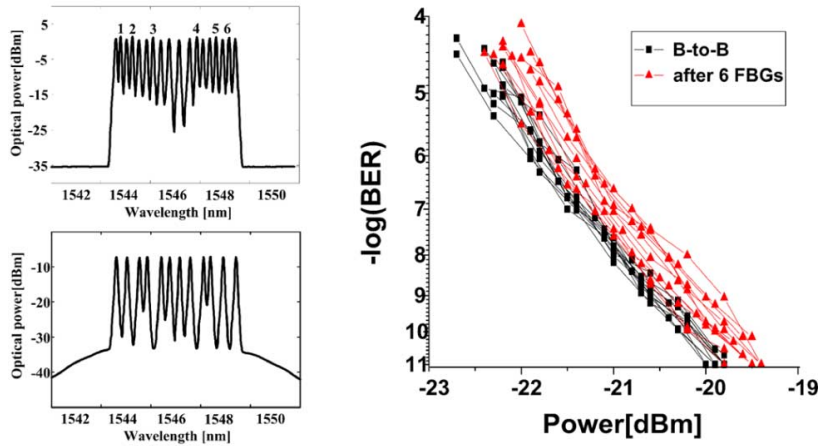

b)

Fig. 2. Optical spectra of the packets before and after the label extractor and BER curves for: (a) 160-Gb/s RZ-OOK; (b) 120-Gb/s NRZ-DPSK.

are shown in Fig. 2. For 160-Gb/s RZ-OOK, error-free operation with 0.6-dB power penalty was measured [see Fig. 2(a)]. Similarly, less than $0.4 \mathrm{~dB}$ of power penalty was measured for the 120-Gb/s NRZ-DPSK format. Those results indicate that in-band labeling can be used as optical address technique with 160-Gb/s RZ-OOK and 120-Gb/s NRZ-DPSK payload formats without compromising the signal quality.

Next, we demonstrate the switching performance of a $1 \times 64$ OPS for $160-\mathrm{Gb} / \mathrm{s}$ RZ-OOK and 120-Gb/s NRZ-DPSK packets. The experimental setup employed is the same reported in Fig. 1. The packets have a duration of $6.4 \mathrm{~ns}$ and are separated by a 3 -ns guard time. The optical power of the input packets before the OPS was $3 \mathrm{dBm}$. In the experiment, we investigated the behavior of a $1 \times 64$ switch by using only two optical gates and $18-\mathrm{dB}$ attenuator that accounts for the 1 by 64 splitting losses. Using two optical gates is sufficient to evaluate the crosstalk between the output ports as well as the switching dynamics. 


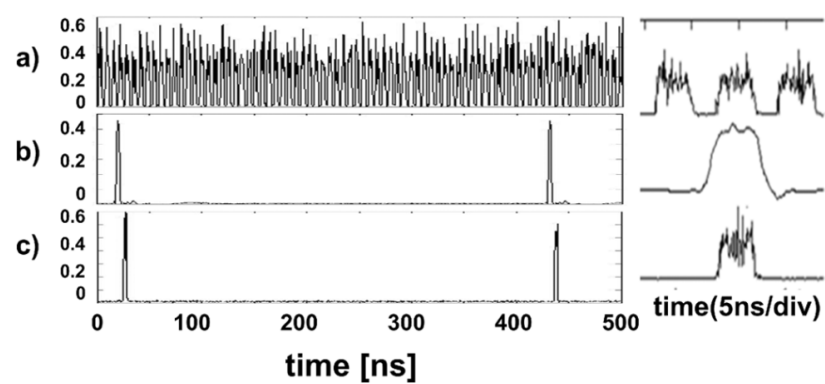

Fig. 3. Measured traces at different points of the OPS for $160-\mathrm{Gb} / \mathrm{s}$ RZ-OOK: (a) input packets; (b) switching control; (c) switched packets. A magnification of the traces with 5 -ns/div timescale is also reported.

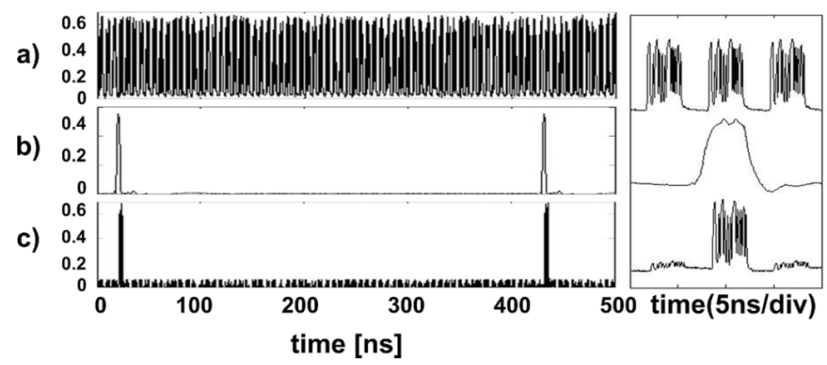

Fig. 4. Measured traces of the OPS for 120-Gb/s NRZ-DPSK: (a) input packets; (b) switching control; (c) switched packets.

Figs. 3 and 4 show the time evolution of the optical packets along the OPS for the $160-\mathrm{Gb} / \mathrm{s}$ RZ-OOK and $120-\mathrm{Gb} / \mathrm{s}$ NRZ-DPSK data packets, respectively. The signal produced by the combinatory network, which is used as a control signal of the optical gates, is shown in Figs. 3(b) and 4(b). The electrical voltage of the control signal generated by the combinatory network was $4.5 \mathrm{~V}$, which is sufficient to drive the optical gate without additional amplifiers. The control opens one optical gate, switching the packet to one of the 64 outputs. The 160-Gb/s RZ-OOK switched packet and the $120-\mathrm{Gb} / \mathrm{s}$ NRZ-DPSK switched packet at the output of the gate are reported in Figs. 3(c) and 4(c), respectively. The measured crosstalk between the output ports was higher than $18 \mathrm{~dB}$. At the receiver, the $160-\mathrm{Gb} / \mathrm{s}$ OOK was demultiplexed to $40 \mathrm{~Gb} / \mathrm{s}$ by an electroabsorption modulator [10]. The measured BER of the switched packet for the $160-\mathrm{Gb} / \mathrm{s}$ RZ-OOK and $120-\mathrm{Gb} / \mathrm{s}$ NRZ-DPSK are reported in Fig. 5(a) and (b), respectively. Error-free operation was obtained with $1.6 \mathrm{~dB}$ of power penalty compared to the back-to-back payload BER for the $160-\mathrm{Gb} / \mathrm{s}$ RZ-OOK packets, and $0.9 \mathrm{~dB}$ of power penalty was measured for the $120-\mathrm{Gb} / \mathrm{s}$ NRZ-DPSK packets.

\section{CONCLUSION}

We have demonstrated error-free operation with 1.6 and $0.9 \mathrm{~dB}$ of penalty of a $1 \times 64$ OPS that transparently routes with multiple data formats and data bit rates, namely $160-\mathrm{Gb} / \mathrm{s}$ RZ-OOK and 120-Gb/s DPSK packets. Employing the in-band labels technique, the packets can be processed without the need to reconfigure the label processor and the switch when changing data format and bit rate. We have shown that by using six labels, $64=2^{6}$ addresses can be encoded without additional spectral occupation. This makes the in-band labeling technique scalable within the limited payload bandwidth. Moreover, parallel and
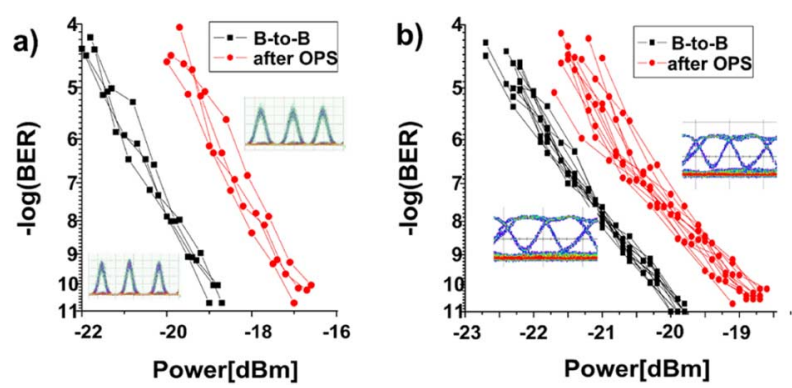

Fig. 5. BER measured at the OPS output. (a) 160-Gb/s RZ-OOK and eye diagrams. Time scale is $2 \mathrm{ps} / \mathrm{div}$. (b) $12 \times 10 \mathrm{~Gb} / \mathrm{s}$ NRZ-DPSK of the output packets and eye diagrams. Time scale is $100 \mathrm{ps} / \mathrm{div}$.

asynchronous labels extraction by passive optical filters has several advantages: the payload is kept in the optical domain, no guard-time and precise synchronization between label and payload is required. The parallel processing allows for using a simple asynchronous electronic combinatory network to generate on the fly the control signals of the gates with a latency $<3 \mathrm{~ns}$. This avoids the long latency due to the address acquisition time and clocked serial-to-parallel conversion. Finally, the low power penalty $(<0.6 \mathrm{~dB})$ operation after six labels extraction and the capability of the asynchronous electronic combinatory network to operate with large number of labels for driving $2^{N}$ optical gates (output ports), suggest that this technique is scalable in terms of in-band labels and at least eight labels can be attributed, scaling the OPS to 256 output ports. For label swapping operation, new labels can be inserted by using the technique presented in [12].

\section{REFERENCES}

[1] C. Schmidt-Langhorst et al., "Generation and coherent time-division demultiplexing of up to $5.1 \mathrm{~Tb} / \mathrm{s}$ single channel 8-PSK and 16-QAM," in Proc. OFC 2009, San Diego, CA, 2009, Paper PDPC6.

[2] A. H. Gnauck et al., "25.6-Tb/s C+L-band transmission of polarization-multiplexed RZ-DQPSK signals," in Proc. OFC 2007, Anaheim, CA, 2007, Paper PDP19.

[3] H. Takahashi, A. Al Amin, S. L. Jansen, I. Morita, and H. Tanaka, "DWDM transmission with $7.0-\mathrm{bit} / \mathrm{s} / \mathrm{Hz}$ spectral efficiency using $8 \times 65.1-G b i t / s$ coherent PDM-OFDM signals," in Proc. OFC 2009, San Diego, CA, 2009, Paper PDPB7.

[4] X. Zhou et al., " $32 \mathrm{~Tb} / \mathrm{s}(320 \times 114 \mathrm{~Gb} / \mathrm{s})$ PMD-RZ-8QAM transmission over 580 km of SMF-28 ultra-low-loss fiber," in Proc. OFC 2009, San Diego, CA, 2009, Paper PDPB4.

[5] R. S. Tucker, "Optical packet-switched WDM networks: A cost and energy perspective," in Proc. OFC 2008, San Diego, CA, 2008, Paper OMG1.

[6] S. J. B. Yoo, "Optical packet and burst switching technologies for the future photonic internet," J. Lightw. Technol., vol. 24, no. 12, pp. 4468-4492, Dec. 2006.

[7] D. J. Blumenthal, "Optical packet switching," Lasers and Electro-Optics Society (LEOS 2004), vol. 2, pp. 910-912, 2004.

[8] D. Klonidis et al., "OPSnet: Design and demonstration of an asynchronous high-speed optical packet switch," J. Lightw. Technol., vol. 23, no. 10, pp. 2914-2925, Oct. 2005.

[9] N. Calabretta et al., "Scalable optical packet switch for optical packets with multiple modulation formats and data rates," in Proc. ECOC 2009, Vienna, Austria, 2009, Paper We 6.3.4.

[10] N. Calabretta et al., "All-optical label swapping of scalable in-band address labels and $160 \mathrm{~Gb} / \mathrm{s}$ data packets," J. Lightw. Technol., vol. 27, no. 3, pp. 214-223, Feb. 1, 2009.

[11] H. J. S. Dorren, N. Calabretta, and O. Raz, "A 3-stage Clos architecture for high-throughput optical packet switching," in Proc. APC-CE, Shanghai, China, 2009, Paper FT6.

[12] N. Calabretta et al., "160 Gb/s all-optical packet switching with label rewriting," in Proc. ECOC 2008, Brussel, 2008, Paper Th 3.F.3. 